\title{
A bi-dimensional classification and characterization of enterprise social media users
}

\author{
Kirchner, Kathrin; Jørgensen, Rasmus; Bolisani, Ettore; Scarso, Enrico
}

Published in:

Measuring Business Excellence

Link to article, DOI:

10.1108/MBE-11-2020-0155

Publication date:

2022

Document Version

Publisher's PDF, also known as Version of record

Link back to DTU Orbit

Citation (APA):

Kirchner, K., Jørgensen, R., Bolisani, E., \& Scarso, E. (2022). A bi-dimensional classification and characterization of enterprise social media users. Measuring Business Excellence, 26(1), 39-51. https://doi.org/10.1108/MBE-11-2020-0155

\section{General rights}

Copyright and moral rights for the publications made accessible in the public portal are retained by the authors and/or other copyright owners and it is a condition of accessing publications that users recognise and abide by the legal requirements associated with these rights.

- Users may download and print one copy of any publication from the public portal for the purpose of private study or research.

- You may not further distribute the material or use it for any profit-making activity or commercial gain

- You may freely distribute the URL identifying the publication in the public portal 


\section{A bi-dimensional classification and characterization of enterprise social media}

users

\section{Kathrin Kirchner, Rasmus Jørgensen, Ettore Bolisani and Enrico Scarso}

\begin{abstract}
Purpose - Enterprise social media (ESM) platforms are rapidly diffusing in the business context because they can bring substantial benefits to companies by enhancing their knowledge management (KM) processes. However, such benefits materialize only if active employee participation is ensured. Therefore, it is crucial to understand how individual employees use an ESM platform to assist their knowledge-related activities. This paper contributes to this topic by proposing a classification of ESM users based on two dimensions: frequency and type (active or passive) of use.

Design/methodology/approach - The paper presents the results of a survey of 262 employees of an international engineering service company that has adopted an ESM platform to support its KM processes. Statistical methods (e.g. ANOVA, Tukey's b) were applied to verify the usefulness of the proposed typology and identify the main aspects that characterize the different user groups.

Findings - The survey results confirm the existence of different types of ESM users and provide the empirical basis for developing a bi-dimensional classification from which four user groups were derived and characterized: frequent contributors, sporadic contributors, frequent lurkers and sporadic lurkers.

Research limitations/implications - The main limitation is that only one company in one sector with specific knowledge needs and capabilities was investigated.

Practical implications - The study provides useful suggestions for how to promote the use of an ESM and particularly for how to encourage less frequent and less active users to increase their participation in a platform.
\end{abstract}

Originality/value - The paper contributes to a better understanding of how employees approach ESM by identifying factors that characterize different user groups.

Keywords Survey, Knowledge management, Enterprise social media, Contributor, Lurker, Users'typology

Paper type Research paper

\section{Introduction}

Enterprise social media (ESM) are social media platforms arranged for use by a company's employees (Leonardi et al., 2013; Hacker, 2017). The application of ESM is rapidly becoming common in the business context, as this technology is increasingly deemed to be crucial for future competition. Many scholars emphasize that ESM can bring substantial benefits to companies and enhance their knowledge management (KM) processes (Nisar et al., 2019). In particular, various studies affirmed that ESM platforms can play a crucial role in facilitating internal knowledge sharing and communication for organizations (Razmerita et al., 2016). This is why ESM has attracted significant attention from professional and academic fields (Ahmed et al., 2019). From the pioneering paper by Levy (2009) to recent ones (Kane, 2017; Archer-Brown and Kietzmann, 2018), the opinion that ESM and KM are a "perfect couple" (Helms et al., 2017) has been consolidating. However, despite scholars' opinions, the introduction of
Kathrin Kirchner is based at the Department of Management, Technical University of Denmark, Lyngby, Denmark. Rasmus Jørgensen is based at the Technical University of Denmark, Lyngby, Denmark. Ettore Bolisani and Enrico Scarso are both based at the DTG, Università degli Studi di Padova, Padova, Italy.

Received 23 November 2020 Revised 12 January 2021 Accepted 10 February 2021

(c) Kathrin Kirchner, Rasmus Jørgensen, Ettore Bolisani and Enrico Scarso. Published by Emerald Publishing Limited. This article is published under the Creative Commons Attribution (CC BY 4.0) licence. Anyone may reproduce, distribute, translate and create derivative works of this article (for both commercial and noncommercial purposes), subject to full attribution to the original publication and authors. The full terms of this licence maybe seen at http://creativecommons.org/licences/by/4.0/ legalcode 
ESM in the business context remains in a preliminary stage (Ammirato et al., 2019) and in many cases, it seems not to have produced the expected outcomes.

This occurs because the benefits emphasized by scholars can materialize only if active and constant use of ESM by individual employees is ensured (Guinan et al., 2014; Mäntymäki and Riemer, 2016). Therefore, it is essential to better understand how companies adopt an ESM platform and how employees get support for their knowledge-related activities by using it. This is why the literature has paid attention to the analysis of the level of participation and the type of activity performed by users of such platforms (Schwade and Schubert, 2019). Although "frequency of use" is the most considered dimension for classifying different ESM user groups, scholars also consider other dimensions, as the distinction between passive and active users, sometimes called "posters" and "lurkers" (Engler and Alpar, 2018; Chin et al., 2020). Even if it can be assumed that active users also frequently use ESM (or vice versa, passive users are sporadic users), the relationship between the two dimensions deserves further investigation, not only to find confirmation but also to understand whether a new typology can be derived from these two dimensions.

In this paper, based on an analysis of relevant literature and the results of a survey conducted among 262 employees of an international project-based service company, we propose a new ESM user typology. Using statistical analysis of the survey data, we identify and examine the main aspects that distinguish the different user types.

The paper is organized as follows. In Section 2, we illustrate the conceptual background of the study, while in Section 3 we describe the research goals and method. In Section 4, we present the results and in Section 5, we discuss them. In Section 6, we present conclusions, academic and managerial implications and the limitations of the study.

\section{Background: enterprise social media user typology}

Scholars agree that many ESM platforms fail because they are underused by the workforce (Guinan et al., 2014; Alarifi et al., 2015; Giermindl et al., 2018). Therefore, there is a need to understand how companies can motivate and encourage employees to use such platforms more intensively by considering different behaviors and forms of use (Hacker and Bodendorf, 2017). Empirical evidence shows that ESM users perform various activities (ranging from simply consuming to producing and distributing content) and with different frequencies. Thus, scholars analyze and classify the different behaviors adopted by ESM users (Schwade and Schubert, 2019; Hacker and Riemer, 2020).

The spread of online communities, spurred by new social media applications, has led to the introduction of new terms to indicate possible user behaviors, e.g. posters and lurkers. The term "poster" indicates users who show active behavior by posting new content, replying to or commenting on content posted by others and so on. Conversely, the term "lurker" denotes users who observe the community activity but do not actively contribute to its development.

Research on enterprise collaboration systems (which include ESM) user typology is fragmented and offers many classifications that are based on different aspects and dimensions, such as type of use, frequency of use and variety of use. Schwade and Schubert (2019) identified in a literature review 102 definitions of user types, which they summarized in six main typologies: creators, contributors, lurkers, inactive, non-users and users without an account. Creators and contributors are active users, with the difference that creators upload new content, while contributors edit and comment on existing information. Lurkers are pure consumers of knowledge but play an important role in building the community's network. The last three user types refer to employees who are not active at all on a platform because they did not use it for a long time, never logged in or never possessed login information. 
Schwade and Schubert (2019) also revealed that scholars focused on the role and characteristics of lurkers, while the discussion of other user types is limited. Furthermore, there is no consensus on the definition of the individual types. For instance, they found 22 different definitions for a lurker on a wide spectrum, ranging from a non-regular poster (Han et al., 2014) to someone who is only consuming information (Brandtzæg, 2010). Moreover, the distinction between contributors and creators is unclear, as contributors can post new information from time to time.

Scholars' strong interest in lurkers is related to the 90-9-1 rule that applies in online communities (Nielsen, 2006): 90\% of users behave as lurkers, who read or observe, but do not contribute; $9 \%$ of users contribute from time to time, but they have other priorities. Only $1 \%$ of users are very active and account for most contributions. This rule, originally defined for internet users, seems to be applicable in the business context, even if with different percentages, as some empirical investigations have revealed (Oettl et al., 2018; Schwade and Schubert, 2019).

The typologies used by ESM scholars to differentiate and analyze user behaviors generally focus on a single dimension. In particular, ESM scholars tend to distinguish between content contributors (posters) and content consumers (lurkers) and investigate the factors that drive the behaviors of these two groups (Alarifi et al., 2015; Engler and Alpar, 2018; Chin et al., 2020). We identified only two papers that discuss user typologies with two dimensions (Giermindl et al., 2018; Oettl et al., 2018).

The qualitative study by Oettl et al. (2018) distinguishes different user types according to two dimensions: individual openness to ESM (i.e. the individual's attitude toward the technology and perceived ability to use it) and perceived task fit (i.e. the perceived usefulness of the platform for the specific task). With such dimensions, which are derived from technology acceptance theories and models (Ngai et al., 2015), the authors identified four user archetypes: power users (denoted by high openness and high task fit), limited users (denoted by high openness and low task fit), reluctant users (denoted by low openness and high task fit) and repudiators (denoted by low openness and low task fit). Furthermore, Oettl et al. identified two mixed user types: hidden champions (placed halfway between limited and power users) and question marks (placed halfway between repudiators and limited users). The study results suggest that the different groups have different perceptions of the value added by the platform, as well as the obstacles to its usage, which has relevant implications for managers who want to promote the use of the platform.

Giermindl et al. (2018) provided a classification that can be regarded as bi-dimensional. The authors used social exchange theory to examine why the motivations for participating in ESM differ for posters and lurkers. This theoretical approach suggests that, within an ESM platform, individuals exchange socioemotional resources and thus, the (active or passive nature) nature of their participation is affected by the motivational factors that characterize a social exchange, such as reputation, common identity, common bond, social interaction and community commitment. Giermindl et al. further split the two groups based on the frequency of their participation into the following groups: super frequent posters, frequent posters, infrequent posters, frequent lurkers and infrequent lurkers. Giermindl et al.'s general findings indicate that posters show considerably higher mean values for all the five motivational aspects compared to lurkers.

Lurkers might be crucial for the success of an ESM platform. Although initially, the term had a negative connotation, their role was revaluated in the literature, especially because they provide the "necessary" audience for posters (Ridings et al., 2006; Cranefield et al., 2015). Furthermore, even consumption alone helps the whole users' community to increase its knowledge pool, transfer it and apply where it is needed (Pohjola and Puusa, 2016; Engler and Alpar, 2018). In this regard, Havakhor et al. (2018) suggested naming the individuals who only consume content "seekers," as this term has a positive connotation. 
In conclusion, studies analyzing the factors that distinguish the different types of ESM users are still fragmented and provide partially contrasting results. In addition, most of the proposed typologies are inconsistent because they mix different dimensions, such as type of use, frequency of use and variety of purposes for use (Schwade and Schubert, 2019). In light of this, we proposed a bi-dimensional classification of ESM users and apply it to analyzing the case company that adopted an ESM platform to support employees' KM activities. As this company has a clear purpose for ESM platform use, the type (active or passive) and the frequency of use are the focus of this study.

\section{Research goals and method}

\subsection{Research questions}

The literature discussion about user typologies in enterprise social media leads to two research questions:

RQ1. Can a bi-dimensional classification based on the type and frequency of use identify and clearly distinguish different types of ESM users?

RQ2. Which factors characterize the different user types derived from such bidimensional classification?

\subsection{Research method}

To answer the research questions, we investigated how members of internal communities of practice in a global engineering company use an ESM platform to access and interact within their communities. We solicited the perceptions of the platform users with a 22question survey. In addition to demographic questions, we asked which knowledge sources and need for information the employees have, how frequently they use the platform to access their main community, what activities they perform, the difficulties they perceive in using the platform to interact with other members and their satisfaction with their communities. In particular, we asked respondents to indicate how frequently they access their communities via the platform and the type of use. Questions either used a five-point Likert scale or were multiple-choice. We added a final open-answer question to receive more opinions about their community and specifically about what they think is missing. The survey was preceded by a letter that explained the study's goals and modality; the letter also informed respondents that their anonymity was guaranteed. We collected data via the survey between September and October 2018. As the survey was accessible from the Connect platform, we collected data only from users of the platform. To analyze the data and answer the research questions, we used descriptive statistics, conceptual content analysis of the open answers and one-factorial ANOVA and Tukey's b post hoc tests to detect differences between the identified user groups.

\section{Findings}

\subsection{Case company}

The case company is a global engineering company in the pharmaceutical industry, with around 2,000 employees in 15 offices in Europe, China, India and the USA. Communities of practice, which the company calls communities of interest (Cols), have assumed a central part of the company's strategy to become a world-leading pharma engineering company, which has a local presence and uses the knowledge of experts around the world.

Since 2008, the company has organized 20 global Cols, whose size at the time of the survey ranged from 67 to 373 members; approximately 1,400 project execution employees were members of at least one Col. Participation is voluntary and the Cols define their own tasks, are responsible for stewarding knowledge within the enterprise and have a long-term 
focus. Cols are in charge of writing global engineering standards and implementing best engineering practices derived from projects throughout the world. Several information and communication technologies, tools including the ESM platform Connect, which was introduced around five years ago, support the communities in knowledge sharing. Each Col has a community leader (called chairman in the company) who is responsible for the community and key members' engagement. He or she is also responsible for the administrative tasks of inviting members to meetings, reporting on Col performance, maintaining a dialogue with the Col board and following up on the budget. A Col has several key members who are appointed voluntarily to the position because they are recognized experts within their field and these members are central to developing knowledge, sharing knowledge and answering questions. Basic members have no responsibilities but contribute to knowledge sharing and development.

\subsection{Deriving a bi-dimensional user classification}

We received 262 valid answers from the employees of the case company. Table 1 provides an overview of the demographics of the survey participants.

Regarding the frequency of use as one dimension of the proposed classification scheme, we defined a frequent user as a "person who uses Connect to access his or her Col at least once a week," while a sporadic user is an "individual who is active only once a month or more rarely." Furthermore, we asked employees whether they perceived themselves as passive users or actively involved on the platform, e.g. by answering questions or motivating their colleagues to contribute. From these two dimensions, use frequency and type of use, four user groups were derived, as indicated in Table 2, which are named following the definition typically used in the literature (Section 2), i.e. frequent contributors, sporadic contributors, frequent lurkers and sporadic lurkers.

\section{Table 1 Demographics of survey participants $(n=262)$}

Items

Position in the company

Manager

Project/Engineering manager $\quad 19.3$

$\begin{array}{lr}\text { Engineer/Specialist } & 72.7\end{array}$

Missing

Length of working in the company

$0-2$ years

21.6

2-5years

29.5

5-10 years

10-15 years

More than 15 years

13.3

Missing

Length of membership in primary $\mathrm{Col}$

0-6 month

6 month-1 year

1-2 years

2-4 years

Missing

Role in primary $\mathrm{Col}$

Chairman 
Table 2 User groups according to frequency and kind of use

\begin{tabular}{lll} 
User group & Active user & Passive user \\
\hline Frequent user & $46.9 \%$ frequent contributors & $9.2 \%$ frequent lurkers \\
Sporadic user & $21.4 \%$ sporadic contributors & $22.5 \%$ sporadic lurkers
\end{tabular}

All user types could be identified in the data sample. The group of frequent users (56.1\% of respondents) was slightly bigger than the group of sporadic users, which can be mainly explained by the fact that the survey was administered online with Connect and thus, the survey reached frequent users more easily. This is also why $68.3 \%$ of respondents indicated they were active users. The high share of active users, much higher than which usually characterizes a social media platform, may be because the platform is used within a favorable organizational context as communities of practice, where knowledge-sharing activities are naturally stimulated. The two groups sporadic contributors and frequent lurkers should be mentioned, as their presence confirmed that the two dimensions seem to be useful to better identify the different user behaviors. To answer research question 2 , in the following section, we analyze the characteristics of these user groups.

\subsection{Characterizing the identified user groups}

Table 3 provides an overview of the demographic characteristics of the four groups. Half of the engineers and more than half of the managers perceive themselves as frequent contributors. For project and engineering managers, we do not see a clear distinction between frequent contributors and sporadic lurkers. Project and engineering managers may also use other tools to coordinate their teams and Cols are seen as a means for finding information related to daily work more than as a coordination tool. The survey showed that chairmen and key members fulfill their roles well because the majority consider themselves frequent contributors. All chairmen perceived themselves as contributors, even if they had more or less intense frequency. Regarding the other two demographic characteristics on the questionnaire, that is, length of membership in a Col and length of employment at the company, no patterns were found. To sum up, the roles played in the company and in the community are related to the type of use made of the platform, while the company and the community seniority are not.

We performed an ANOVA to identify differences between the four groups. Table 4 lists the mean values and standard deviations of Likert-scaled variables that showed significant Ftest results $(p=0.05)$. The first four factors concern the relevance of different knowledge sources for the employee's own daily job, which indicates the importance of his or her cognitive needs and the second five how much Cols help in satisfying the employee's different needs. The other factors, such as technical and organizational obstacles to

Table 3 Demography of user groups

\begin{tabular}{|c|c|c|c|c|}
\hline Items & $\begin{array}{l}\text { Frequent contributor } \\
\qquad(n=123)(\%)\end{array}$ & $\begin{array}{l}\text { Frequent lurker } \\
\qquad(n=24)(\%)\end{array}$ & $\begin{array}{c}\text { Sporadic contributor } \\
\quad(n=56)(\%)\end{array}$ & $\begin{array}{c}\text { Sporadic lurker } \\
(n=59)(\%)\end{array}$ \\
\hline \multicolumn{5}{|l|}{ Position in the company } \\
\hline Engineer/Specialist & 50.0 & 10.9 & 20.8 & 18.2 \\
\hline Project/Engineering manager & 31.4 & 5.9 & 23.5 & 39.2 \\
\hline Manager & 55.6 & 0.0 & 22.2 & 22.2 \\
\hline \multicolumn{5}{|l|}{ User role in primary Col } \\
\hline Chairman & 89.5 & 0.0 & 10.5 & 0.0 \\
\hline Key member & 77.4 & 1.9 & 17.0 & 2.8 \\
\hline Member & 34.4 & 12.2 & 23.3 & 30.2 \\
\hline
\end{tabular}


Table 4 Mean values of significant variables in ANOVA analysis

\begin{tabular}{|c|c|c|c|c|c|c|}
\hline Group of variables & Variable & F-value (sig.) & $\begin{array}{l}\text { Frequent } \\
\text { contributor: } \\
\text { mean }(S D)\end{array}$ & $\begin{array}{l}\text { Frequent } \\
\text { lurker: mean } \\
\quad(S D)\end{array}$ & $\begin{array}{l}\text { Sporadic } \\
\text { contributor: } \\
\text { mean }(S D)\end{array}$ & $\begin{array}{l}\text { Sporadic } \\
\text { lurker: mean } \\
\text { (SD) }\end{array}$ \\
\hline \multirow[t]{4}{*}{$\begin{array}{l}\text { Relevance of } \\
\text { knowledge sources } \\
\text { for the job }\end{array}$} & $\begin{array}{l}\text { Relevance of external } \\
\text { knowledge sources for own job } \\
\text { (magazines, conferences) }\end{array}$ & $\begin{array}{l}F=6.047 \\
\text { Sig } 0.001\end{array}$ & $3.37(1.134)$ & $2.83(1.239)$ & $2.96(1.159)$ & $2.64(1.119)$ \\
\hline & $\begin{array}{l}\text { Relevance of Connect as } \\
\text { knowledge source for own job }\end{array}$ & $\begin{array}{l}F=8.818 \\
\text { Sig } 0.000\end{array}$ & $3.58(0.950)$ & $3.09(1.041)$ & $3.05(0.862)$ & $2.84(1.121)$ \\
\hline & $\begin{array}{l}\text { Relevance of formal meetings } \\
\text { for own job }\end{array}$ & $\begin{array}{l}F=2.698 \\
\text { Sig } 0.046\end{array}$ & $3.88(0.829)$ & $3.92(0.830)$ & $3.61(1.039)$ & $3.53(1.040)$ \\
\hline & $\begin{array}{l}\text { Importance of information } \\
\text { about new tech solutions for } \\
\text { job }\end{array}$ & $\begin{array}{l}F=7.304 \\
\text { Sig } 0.000\end{array}$ & $4.07(0.825)$ & $3.50(1.103)$ & $3.51(0.998)$ & $3.51(1.165)$ \\
\hline \multirow[t]{5}{*}{ Satisfaction with Col } & $\begin{array}{l}\text { Satisfied with Col fulfilment of } \\
\text { own needs }\end{array}$ & $\begin{array}{l}F=15.99 \\
\text { Sig } 0.000\end{array}$ & $3.55(0.727)$ & $3.17(0.702)$ & $3.11(0.908)$ & $2.71(0.811)$ \\
\hline & $\begin{array}{l}\text { Satisfied with level of } \\
\text { collaboration in Col }\end{array}$ & $\begin{array}{l}F=6.629 \\
\text { Sig } 0.000\end{array}$ & $3.40(0.939)$ & $3.21(0.779)$ & $3.02(0.863)$ & $2.79(0.881)$ \\
\hline & $\begin{array}{l}\text { Satisfied with finding often } \\
\text { answers to questions in Col }\end{array}$ & $\begin{array}{l}F=15.514 \\
\text { Sig } 0.000\end{array}$ & $3.44(0.841)$ & $3.04(0.955)$ & $2.89(0.824)$ & $2.49(1.054)$ \\
\hline & $\begin{array}{l}\text { Satisfied with Col ability to } \\
\text { receive own ideas }\end{array}$ & $\begin{array}{l}F=8.019 \\
\text { Sig } 0.000\end{array}$ & $3.63(0.969)$ & $3.33(0.816)$ & $3.20(0.826)$ & $2.95(0.911)$ \\
\hline & $\begin{array}{l}\text { Satisfied with Col keeping up } \\
\text { with industry }\end{array}$ & $\begin{array}{l}F=5.968 \\
\text { Sig } 0.001\end{array}$ & $3.58(0.864)$ & $3.58(1.018)$ & $3.14(0.819)$ & $3.09(0.880)$ \\
\hline
\end{tabular}

platform use, did not show any statistically significant difference among the members of the four groups.

Looking at the results shown in Table 4, sporadic lurkers show the lowest mean values in all variables. Frequent contributors present much higher values (apart from the relevance of formal meetings). Therefore, it seems reasonable to presume that sporadic lurkers and frequent contributors are very different, especially concerning their knowledge needs which are greater for frequent contributors. Furthermore, the level of satisfaction with all the benefits linked to belonging to the Col decreased from frequent contributors to frequent lurkers to sporadic contributors to sporadic lurkers. This last point highlights the existence of a relationship between the use of the ESM platform and the perceived usefulness of Cols, which seems to confirm previous literature on the existence of a synergic link between communities and ESM (Annabi and McGann, 2013; Helms et al., 2017).

We used Tukey's b post hoc test to explore the differences between user groups $(p=0.05)$ for all the variables in Table 4 in more detail. The results reported in Table 5 reveal the different subgroups that could be found. In some cases, the groups can be distinguished clearly (such as in "satisfied with Col fulfillment of my needs," where three subgroups were found). In other cases, like "relevance of external knowledge sources," frequent contributors and sporadic lurkers clearly are in two different groups, while frequent lurkers and sporadic contributors could be assigned to both groups according to Tukey's b test. In general, frequent contributors can be distinguished from sporadic lurkers, as they are in eight of nine variables in different groups and from sporadic contributors (in four of the nine variables). Frequent lurkers and sporadic contributors are more similar to each other (as they are in the same subgroup in more cases) than they are similar to sporadic lurkers. This result suggests that the investigated factors influence frequency more than a type of use.

We also asked participants in an open question about what they thought their primary Col lacked. The results were analyzed via qualitative conceptual content analysis. We used an inductive approach and during the interactive coding process identified six different problem areas. We also counted the frequencies of the named problems per user group. 
Table 5 Homogeneous subsets for ANOVA significant variables according to Tukey b test (mean values)

Significant variables according to ANOVA

Subset for $\alpha=0.05$

Relevance of external knowledge sources for own job (magazines, conferences)

Frequent contributor

1

2

Frequent lurker

2.83

Sporadic contributor

Sporadic lurker

2.83

2.96

2.64

Relevance of Connect as knowledge source for own job

Frequent contributor

Frequent lurker

Sporadic contributor

Sporadic lurker

Relevance of formal meetings for own job

Frequent contributor

Frequent lurker

Sporadic contributor

Sporadic lurker

3.05

2.84

Importance of information about new tech solutions for job

Frequent contributor

Frequent lurker

Sporadic contributor

Sporadic lurker

Satisfied with Col fulfilment of own needs

Frequent contributor

Frequent lurker

Sporadic contributor

Sporadic lurker

4.07

3.50

3.51

3.51

Satisfied with level of collaboration in Col

Frequent contributor

Frequent lurker

Sporadic contributor

Sporadic lurker

3.55

3.17

3.11

2.71

3.40

3.21

3.02

3.21

3.02

2.79

Satisfied with finding often answers to questions in Col

Frequent contributor

Frequent lurker

3.44

3.04

3.04

2.89

2.89

Sporadic lurker

Satisfied with Col ability to receive own ideas

Frequent contributor

Frequent lurker

Sporadic contributor

Sporadic lurker

Satisfied with Col keeping up with industry

Frequent contributor

Frequent lurker

Sporadic contributor

3.14

3.14

Sporadic lurker

Table 6 lists the most frequent answers and the number of people who mentioned the issue in parentheses. All four groups indicated two problem areas: the need for more participants who are active and making the search of useful content easier. Frequent contributors mentioned the need to find more (and in a different format) topics; they also would even like to contribute more, if they had time. Sporadic contributors mentioned similar topics as the frequent contributors but asked for more support from senior management and a clearer 
Table 6 Results of conceptual content analysis regarding missing issues in the COls ( $n=$ frequency of concept)

\begin{tabular}{|c|c|c|c|c|}
\hline Problem area & Frequent contributors & Frequent lurkers & Sporadic contributors & Sporadic lurkers \\
\hline User activity & - More active participants $(n=18)$ & - More activity $(n=2)$ & $\begin{array}{l}\text { - Missing active people }(n= \\
\text { 2) }\end{array}$ & $\begin{array}{l}\text { - Missing activity of } \\
\text { other people }(n=2)\end{array}$ \\
\hline Content issues & $\begin{array}{l}\text { - More topics, not only questions } \\
\text { and answers }(n=7)\end{array}$ & $\begin{array}{l}\text { - More and more } \\
\text { updated content }(n=4)\end{array}$ & $\begin{array}{l}\text { - Missing updated content } \\
\text { and links }(n=3)\end{array}$ & \\
\hline Missing time & - More time to contribute $(n=6)$ & & $\begin{array}{l}\text { - Missing time to use Col ( } n \\
=3 \text { ) }\end{array}$ & - No time $(n=3)$ \\
\hline $\begin{array}{l}\text { Finding relevant } \\
\text { information }\end{array}$ & $\begin{array}{l}\text { - Better search possibilities }(n=6) \\
\text { - Access from outside the company } \\
(n=2)\end{array}$ & $\begin{array}{l}\text { - Easier overview about } \\
\text { content that allows to } \\
\text { follow a topic }(n=2)\end{array}$ & $\begin{array}{l}\text { - Better ways to search for } \\
\text { and filter relevant information } \\
(n=4) \\
\text { - Useful rating of articles ( } n \\
=2)\end{array}$ & $\begin{array}{l}\text { - Miss focus on relevant } \\
\text { information }(n=2)\end{array}$ \\
\hline No motivation & & $\begin{array}{l}\text { - Do not need Cols for } \\
\text { own work }(n=1)\end{array}$ & & $\begin{array}{l}\text { - Lack of motivation/ } \\
\text { better to ask colleagues } \\
\text { directly }(n=4)\end{array}$ \\
\hline $\begin{array}{l}\text { Missing support } \\
\text { from management }\end{array}$ & & & $\begin{array}{l}\text { - Support from upper } \\
\text { management/strategy for all } \\
\text { Cols, rewards for higher } \\
\text { quality }(n=2)\end{array}$ & $\begin{array}{l}\text { - Need more support } \\
\text { from management to } \\
\text { integrate in daily work } \\
(n=2)\end{array}$ \\
\hline
\end{tabular}

strategy for all Cols. Frequent lurkers were disappointed with old information and dead links, while sporadic lurkers were not motivated to use their Col because they found it easier to ask their colleagues directly. Sporadic lurkers also complained about their limited time to participate in the Col and similarly to sporadic contributors, about the lack of support from management to integrate such activity in daily work.

\section{Discussion}

\subsection{Characteristics of user groups}

We investigated whether it is possible and likely more useful, to use a bi-dimensional taxonomy to classify ESM users with two dimensions: frequency of use and type of use (RQ1). Different from other authors such as Schwade and Schubert (2019), we focused the classification on users of the platform (we did not include non-users). Furthermore, we did not define different types of lurking and contributing, but users of the ESM platform reported their perceived active (contributors) and passive (lurkers) use, as well their platform use frequency. The results confirmed the bi-dimensional classification of ESM users and therefore answered $R Q 1$, given that a sufficient number of survey respondents were included in all four user types.

We also characterized the four derived user groups to answer $R Q 2$. We found that the groups exhibit significant differences concerning the role played by individuals in the groups. In particular, the large majority of assigned chairmen and key members are frequent contributors, which is completely in line with their role within the community. Conversely, the group of sporadic lurkers is almost exclusively made up of basic members. Moreover, this study showed that different user types have different motivations for using the platform regarding information needs for their job (depending on which of this information can also be found in the Cols) and to what degree the community fulfills their needs for useful and updated information and to collaborate with colleagues. In general, results suggest that the higher the knowledge needs, particularly those concerning new technical solutions and the capability to find answers within the community, the more frequent the respondents' use of the ESM platform. This result is in line with the supporting KM role that scholars assign to such tools (Razmerita et al., 2014).

However, the results show that although frequent contributors clearly distinguish themselves from sporadic lurkers, sporadic users and frequent lurkers are similar in terms 
of cognitive needs and satisfaction with Cols. In particular, Tukey's b post hoc test results did not show differences between sporadic contributors and frequent lurkers. Instead, the latter group is more satisfied with their Col than the former group, which shows that frequency plays a more relevant role in differentiating users' types than the active or passive type of use. This seems to confirm the attention given to this variable as a classification basis by many authors (Holtzblatt et al., 2013).

\subsection{Changing sporadic contributors and lurkers to more frequent users}

Knowing the characteristics of the different user types allows designing and implementing specific initiatives to promote more frequent and active use of the platform. A challenging step is to induce infrequent contributors to contribute more frequently, as well as infrequent lurkers to use Cols more frequently. In this regard, the results in Table 6 show that sporadic users complain about not finding enough useful information in the ESM and of the lack of management support.

To address the first issue, chairmen and key members should not only contribute new knowledge but also take care that outdated knowledge is archived and dead links are removed. In general, better-organized information allows easier and faster retrieval, thus leading to increased use of the platform and the community.

To address the second issue, managers should integrate the work with Cols into employees' daily work routines, make the benefits of contributing to and using the ESM clearer, encourage employees to contribute and give them time to read information and provide answers (Razmerita et al., 2016). In doing this, managers should consider the organizational position of the individual employee. For instance, in the case of the company some factors make project and engineering managers less frequent and active users of the platform, which must be identified to foster their participation.

In the case company, all actions (also offline) that aim at making Cols more useful for members can have a positive impact on the use of the ESM platform in terms of increasing the frequency and the level of contribution. The content provided is a key factor: the more useful and updated content for one's job that is provided, the more frequently and actively the platform will be used. Furthermore, respondents proposed that contributions should be rewarded, especially if they are high quality and therefore, are very useful for colleagues.

\section{Conclusions}

In this study, we used a bi-dimensional typology to classify and analyze how employees of an engineering services company use an ESM platform to access and interact within their communities. The results provided answers to the two research questions; however, the answers were partially unexpected and provide thought-provoking indications.

\subsection{Implications of the study}

The paper has academic and practical implications. From an academic viewpoint, this study confirmed that such a bi-dimensional classification can help better identify the different ESM user groups and understand the factors that affect their behavior. Furthermore, it allows highlighting differences and similarities that describe the various groups. For instance, the results revealed that frequent lurkers and sporadic contributors share some common traits that distinguish them from the other two groups. This paves the way for further empirical research on different factors that characterize and distinguish the different user groups. In addition, future researchers should use the proposed classification in other contexts and confirm whether the characteristics of the different groups are linked to the organizational environment in which the ESM platform is implemented. 
Regarding the practical implications, the results provide useful indications to managers who intend to promote the use of an ESM platform within their company. In particular, the results not only confirm the ineffectiveness of an undifferentiated approach but also suggest that managers' efforts should be primarily directed at sporadic users who are less satisfied with their Col and ask for more managerial support.

\subsection{Limitations}

This study has several limitations. The most important is that results cannot be generalized, as only one company in an industry with specific knowledge needs and capabilities was examined. An aspect that must be considered concerns the fact that the ESM platform operates within a community-based context, which clearly influences the use of the platform. Furthermore, for the sake of speed and simplicity, the survey was distributed through the ESM and not via email, thus reducing the reach. Thus, it is likely that the sample included a larger share of more frequent users than the actual percentage in the company. Finally, the study is based on respondents' self-assessments of their frequency and the type of use as we were not allowed to access the Connect system and conduct an analysis of log data and activities performed. However, researchers on this topic frequently use this method (Ahmed et al., 2019) especially because, differently from what happens using log data, it allows to collect of information about motivations, perceived advantages, etc., that induce people to use ESM. Thus, despite the previous limitations, the findings of the study provide interesting insights that can be the basis for further studies aimed to better understand how new social media tools are used in the business context.

\section{References}

Ahmed, Y.A., Ahmad, M.N., Ahmad, N. and Zakaria, N.H. (2019), "Social media for knowledge-sharing: a systematic literature review", Telematics and Informatics, Vol. 37, pp. 72-112.

Alarifi, A., Sedera, D. and Recker, J. (2015), "Posters versus lurkers: improving participation in enterprise social networks through promotional messages", paper presented at the Thirty-Sixth International Conference on Information Systems, 13-16 Dec., Fort Worth, TX, available at: https://eprints.qut.edu.au/ 87663/ (accessed 10 January 2021).

Ammirato, S., Felicetti, A.M., Della Gala, M., Aramo-Immonen, H., Jussila, J.J. and Kärkkäinen, H. (2019), "The use of social media for knowledge acquisition and dissemination in B2B companies: an empirical study of Finnish technology industries", Knowledge Management Research \& Practice, Vol. 17 No. 1, pp. 52-69.

Annabi, H. and McGann, S.T. (2013), "Social media as the missing link connecting communities of practice to business strategy", Journal of Organizational Computing and Electronic Commerce, Vol. 23 Nos 1/2, pp. 56-83.

Archer-Brown, C. and Kietzmann, J. (2018), "Strategic knowledge management and enterprise social media”, Journal of Knowledge Management, Vol. 22 No. 6, pp. 1288-1309.

Brandtzæg, P.B. (2010), "Towards a unified Media-User Typology (MUT): a meta-analysis and review of the research literature on media-user typologies", Computers in Human Behavior, Vol. 26 No. 5 , pp. 940-956.

Chin, P.Y., Evans, N., Liu, C.Z. and Choo, K.K.R. (2020), “Understanding factors influencing employees' consumptive and contributive use of enterprise social networks", Information Systems Frontiers, Vol. 22 No. 6, pp. 1357-1376.

Cranefield, J., Yoong, P. and Huff, S.L. (2015), "Rethinking lurking: invisible leading and following in a knowledge transfer ecosystem", Journal of the Association for Information Systems, Vol. 16 No. 4, pp. 213-247.

Engler, T.H. and Alpar, P. (2018), "Contribution and consumption of content in enterprise social media", Information Systems Management, Vol. 35 No. 1, pp. 2-14. 
Giermindl, L., Strich, F. and Fiedler, M. (2018), "How do they differ? Analyzing the motivations of posters and lurkers for participation in enterprise social networks", Journal of Information Technology Theory and Application, Vol. 19 No. 2, pp. 89-120.

Guinan, P.J., Parise, S. and Rollag, K. (2014), "Jumpstarting the use of social technologies in your organization", Business Horizons, Vol. 57 No. 3, pp. 337-347.

Hacker, J. (2017), "Enterprise social networks: platforms for enabling and understanding knowledge work?", in Helms, R., Cranefield, J. and van Reijsen, J. (Eds), Social Knowledge Management in Action, Springer International Publishing, Cham, pp. 17-37.

Hacker, J. and Riemer, K. (2020), "Identification of user roles in enterprise social networks: method development and application", Business \& Information Systems Engineering: The International Journal of WIRTSCHAFTSINFORMATIK, pp. 1-21.

Hacker, J. and Bodendorf, F. (2017), "Conceptualising and understanding user behaviour in enterprise social networks: a qualitative analysis", paper presented at the 28th Australasian Conference on Information Systems, 4-6 Dec., Hobart, available at: https://aisel.aisnet.org/ acis2017/41/ (accessed 10 January 2021).

Han, J.Y., Hou, J., Kim, E. and Gustafson, D.H. (2014), "Lurking as an active participation process: a longitudinal investigation of engagement with an online cancer support group", Health Communication, Vol. 29 No. 9, pp. 911-923.

Havakhor, T., Soror, A.A. and Sabherwal, R. (2018), "Diffusion of knowledge in social media networks: effects of reputation mechanisms and distribution of knowledge roles", Information Systems Journal, Vol. 28 No. 1, pp. 104-141.

Helms, R., Cranefield, J. and van Reijsen, J. (Eds) (2017), "Social media and knowledge management: a perfect couple", Social Knowledge Management in Action, Springer International Publishing, Cham, pp. 1-13.

Holtzblatt, L., Drury, J.L., Weiss, D., Damianos, L.E. and Cuomo, D. (2013), "Evaluating the uses and benefits of an enterprise social media platform", Journal of Social Media for Organization, Vol. 1 No. 1, pp. 1-21.

Kane, G.C. (2017), "The evolutionary implications of social media for organizational knowledge management”, Information and Organization, Vol. 27 No. 1, pp. 37-46.

Leonardi, P.M., Huysman, M. and Steinfield, C. (2013), "Enterprise social media: definition, history and prospects for the study of social technologies in organizations", Journal of Computer-Mediated Communication, Vol. 19 No. 1, pp. 1-19.

Levy, M. (2009), "WEB 2.0 implications on knowledge management", Journal of Knowledge Management, Vol. 13 No. 1, pp. 120-134.

Mäntymäki, M. and Riemer, K. (2016), "Enterprise social networking: a knowledge management perspective", International Journal of Information Management, Vol. 36 No. 6, pp. 1042-1052.

Ngai, E.W., Tao, S.S. and Moon, K.K. (2015), "Social media research: theories, constructs and conceptual frameworks", International Journal of Information Management, Vol. 35 No. 1, pp. 33-44.

Nielsen, J. (2006), "90-9-1. rule for participation inequality: lurkers vs. contributors in internet communities", Nielsen Norman Group, available at: www.nngroup.com/articles/participation-inequality/ (accessed 10 January 2021).

Nisar, T.M., Prabhakar, G. and Strakova, L. (2019), "Social media information benefits, knowledge management and smart organizations", Journal of Business Research, Vol. 94, pp. 264-272.

Oettl, C., Berger, T., Böhm, M., Wiesche, M. and Krcmar, H. (2018), "Archetypes of enterprise social network users", paper presented at the 51st HI International Conference on System Sciences, Hilton Waikaloa Village, HI, 3-6 Jan 2018, pp. 2036-2045.

Pohjola, I. and Puusa, A. (2016), "Group dynamics and the role of ICT in the life cycle analysis of community of practice-based product development: a case study", Journal of Knowledge Management, Vol. 20 No. 3, pp. 465-483.

Razmerita, L., Kirchner, K. and Nabeth, T. (2014), "Social media in organizations: leveraging personal and collective knowledge processes", Journal of Organizational Computing and Electronic Commerce, Vol. 24 No. 1, pp. 74-93. 
Razmerita, L., Kirchner, K. and Nielsen, P. (2016), "What factors influence knowledge sharing in organizations? A social dilemma perspective of social media communication", Journal of Knowledge Management, Vol. 20 No. 6, pp. 1225-1246.

Ridings, C., Gefen, D. and Arinze, B. (2006), "Psychological barriers: lurker and poster motivation and behavior in online communities", Communications of the Association for Information Systems, Vol. 18, pp. 329-354.

Schwade, F. and Schubert, P. (2019), "Developing a user typology for the analysis of participation in enterprise collaboration systems", paper presented at the 52nd HI International Conference on System Sciences, Grand Wailea, Maui, HI, 8-11 Nov 2019, pp. 460-469.

\section{Corresponding author}

Enrico Scarso can be contacted at: enrico.scarso@unipd.it

For instructions on how to order reprints of this article, please visit our website: www.emeraldgrouppublishing.com/licensing/reprints.htm

Or contact us for further details: permissions@emeraldinsight.com 